\title{
Granule-Dependent Natural Killer Cell Cytotoxicity to Fungal Pathogens
}

\author{
Henry Ogbomo ${ }^{1,2,3}$ and Christopher H. Mody ${ }^{1,2,4 *}$ \\ ${ }^{1}$ The Calvin, Phoebe and Joan Snyder Institute for Chronic Diseases, University of Calgary, Calgary, AB, Canada, \\ ${ }^{2}$ Department of Microbiology, Immunology and Infectious Diseases, University of Calgary, Calgary, AB, Canada, ${ }^{3}$ Department \\ of Physiology and Pharmacology, University of Calgary, Calgary, AB, Canada, ${ }^{4}$ Department of Internal Medicine, University of \\ Calgary, Calgary, $A B$, Canada
}

OPEN ACCESS

Edited by:

Vincent Vieillard,

Centre National de la Recherche Scientifique (CNRS), France

Reviewed by:

Frank Momburg,

German Cancer Research Center

$(H Z)$, Germany

Sophie Caillat-Zucman,

French Institute of Health and

Medical Research, France

${ }^{*}$ Correspondence: Christopher H. Mody

cmody@ucalgary.ca

Specialty section:

This article was submitted to NK and Innate Lymphoid Cell Biology,

a section of the journal

Frontiers in Immunology

Received: 14 November 2016 Accepted: 28 December 2016

Published: 11 January 2017

Citation:

Ogbomo H and Mody CH (2017)

Granule-Dependent Natural Killer Cell

Cytotoxicity to Fungal Pathogens.

Front. Immunol. 7:692.

doi: 10.3389/fimmu.2016.00692
Natural killer (NK) cells kill or inhibit the growth of a number of fungi including Cryptococcus, Candida, Aspergillus, Rhizopus, and Paracoccidioides. Although many fungi are not dangerous, invasive fungal pathogens, such as Cryptococcus neoformans, cause life-threatening disease in individuals with impaired cell-mediated immunity. While there are similarities to cell-mediated killing of tumor cells, there are also important differences. Similar to tumor killing, NK cells directly kill fungi in a receptor-mediated and cytotoxic granule-dependent manner. Unlike tumor cell killing where multiple NK cell-activating receptors cooperate and signal events that mediate cytotoxicity, only the NKp30 receptor has been described to mediate signaling events that trigger the NK cell to mobilize its cytolytic payload to the site of interaction with C. neoformans and Candida albicans, subsequently leading to granule exocytosis and fungal killing. More recently, the NKp46 receptor was reported to bind Candida glabrata adhesins Epa1, 6, and 7 and directly mediate fungal clearance. A number of unanswered questions remain. For example, is only one NK cell-activating receptor sufficient for signaling leading to fungal killing? Are the signaling pathways activated by fungi similar to those activated by tumor cells during NK cell killing? How do the cytolytic granules traffic to the site of interaction with fungi, and how does this process compare with tumor killing? Recent insights into receptor use, intracellular signaling and cytolytic granule trafficking during NK cell-mediated fungal killing will be compared to tumor killing, and the implications for therapeutic approaches will be discussed.

Keywords: fungal cytotoxicity, tumor cytotoxicity, cytotoxic granules, fungal cytotoxic receptors, fungal cytotoxicity signaling pathways

\section{INTRODUCTION}

In the mid-1970s, two independent groups discovered natural killer (NK) cells when they described their ability to lyse tumor cells without prior exposure $(1,2)$. It is now well established that NK cells are also effective cytotoxic lymphocytes against fungi (3), in addition to their ability to lyse tumors and virus-infected tumor cells (4). NK cell-mediated cytotoxicity is a complex process that involves receptor-mediated binding and signaling, synapse formation, granule polarization, and granule release (5). For tumors, NK cell cytotoxicity is regulated by activating and inhibitory receptors that are expressed on its cell surface. Ligation of these receptors with their cognate ligands triggers downstream signaling events, and a balance in both activating and inhibiting signals tightly 
controls NK cell function. While there are some similarities with respect to NK cell-mediated killing of tumor cells or fungi, some important differences exist. For example, in tumor cell killing, NK cells release perforin and granzyme B as effector molecules, with the perforin-forming pores in the tumor cell membrane, thereby allowing entrance of granzyme B to activate caspases and induce target cell death (6). In the case of fungi killing, there is no reported use of granzyme B. Instead, NK cells release perforin to directly kill Cryptococcus neoformans and Candida albicans $(7,8)$, or granulysin to directly kill Paracoccidioides brasiliensis (9), or IFN-gamma to directly damage Aspergillus fumigatus (10). NK cells also indirectly mediated fungal elimination by secreting IFN-gamma to either mediate fungicidal activity of murine peritoneal exudate cells against $C$. neoformans (11) or mediate phagocytosis of $C$. albicans by splenic macrophages (12) or secrete GM-CSF to promote neutrophil phagocytosis of C. albicans (13). It has also been shown that the receptor and signaling pathway used for cryptococcal killing differs from that used for tumor killing $(14,15)$. This review will focus on the recent insights into activating receptor-mediated signaling and granule trafficking during NK cell killing of fungi compared to that of tumor cells.

\section{RECEPTORS USED BY NK CELLS DURING KILLING}

During tumor cytotoxicity, NK cells use a large number of activating receptors to mediate granule-dependent killing. Such receptors include the natural cytotoxic receptors (NCRs) such as NKp30, NKp44, and NKp46, as well as NKG2D, DNAM-1, 2B4, CD2, NKp80, CD48 and Ly9 (CD229), LFA-1, and CD16 (5, 16-28). Interestingly, no activating receptor was found to be sufficient in inducing degranulation, except when used in combination with other receptors $(5,17,19)$. It is possible that synergy among NK receptors could be required to mediate fungal cytotoxicity as it is in tumor cytotoxicity.

In the context of fungal cytotoxicity, only two NK cellactivating receptors, NKp30 and NKp46, have been identified. The NKp30 receptor was identified as a fungal cytotoxic receptor when antibodies that were generated against an NK cell line, YT, inhibited fungal killing by NK cells. The NKp30 receptor directly recognized and mediated NK cell killing of $C$. neoformans and C. albicans (7) and antibody blocking or siRNA knockdown of NKp30 expression reduced fungal binding and killing (7). More recently, the NKp46 receptor was discovered to directly recognize and mediate killing of Candida glabrata (29). NKp46 was identified as a fungal cytotoxic receptor when soluble NKp46-IgG1 fusion construct specifically bounded multiple fungal adhesins, Epa1, 6, and 7, expressed on C. glabrata and mediated killing of C. glabrata (29). In addition, mice deficient in NCR1 (mouse ortholog of NKp46) could not mediate clearance of systemic C. glabrata infection (29). Since several fungi including Cryptococcus, Candida, Aspergillus, and Coccidioides express adhesins (30), it is interesting to speculate that other fungal adhesins could be recognized by NK cell receptors for fungal cytotoxicity.

\section{SIGNALING PATHWAY ACTIVATED IN NK CELLS DURING KILLING}

Signaling through NK cell-activating receptors triggers cytotoxicity (6). While the molecular pathways that are associated with NK cell killing of tumor target cells have been elucidated [Figure 1; $(6,31)$ ], the pathways associated with NK cell antifungal activity are still being elucidated (Figure 2). In tumor killing, the inhibition of phosphatidylinositol 3-kinase (PI3K) in NK cells blocked p21-activated kinase 1 (PAK1), MAPK kinase (MEK), and extracellular signal regulated kinase (Erk) activation and interfered with cytotoxic granule movement toward the target cells, thereby suppressing NK cytotoxicity (32). Hence, NK cell antitumor signaling follows the sequential activation of PI3K $\rightarrow$ Racl $\rightarrow$ PAK1 $\rightarrow$ MEK $\rightarrow$ Erk $(6,32)$. A Vav1 $\rightarrow$ PLC $\gamma 2 \rightarrow$ Erk sequence has also been reported to mediate cytotoxicity $(31,33)$ and Vav1, which is a guanine exchange factor, activated Rac1 by catalyzing GDP/GTP exchange on Rac1 (34). Similar to tumor killing, fungal killing, demonstrated using Cryptococcus, depended on PI3K $\rightarrow$ Erk signaling (35). However, unlike tumor killing, PLC $\gamma$ was not required for cryptococcal killing (15). Further, in the context of tumor killing, and depending on the activating receptor involved, Src family kinases (SFKs) either directly activated PI3K, leading to Rac and Erk activation, or recruited Vav1 to activate Rac (Figure 1). While the NCRs signal through the PI3K/Rac/Erk axis (6), DNAM-1 and 2B4 signal through the Vav1/Rac/Erk axis (36), and NKG2D transmits its signal through both axes (31, 33, 36-40). Similar to tumor killing, two SFKs, Fyn and Lyn, redundantly mediated NK cell anticryptococcal activity by activating PI3K and Erk1/2 (41). Also, SFK was required to form NK cell-cryptococcal conjugates (15), and NKp30 was required for NK cell-fungal conjugate formation and PI3K-Erk signaling (7), making it likely that NKp30 activated SFK. Unlike in tumor killing where Rac is activated by SFK and is downstream of PI3K,

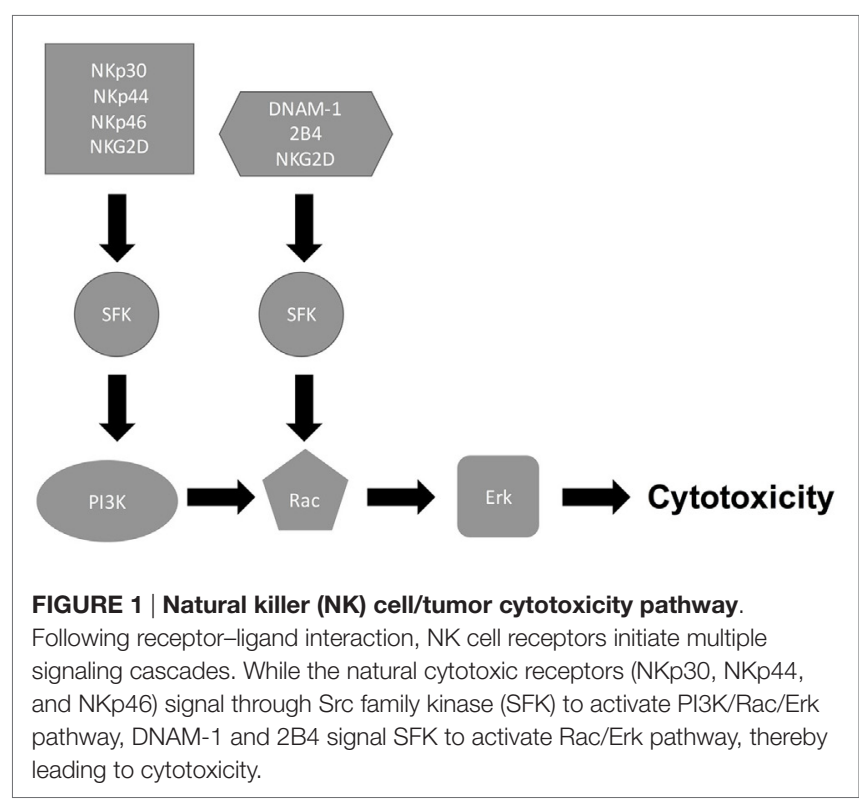




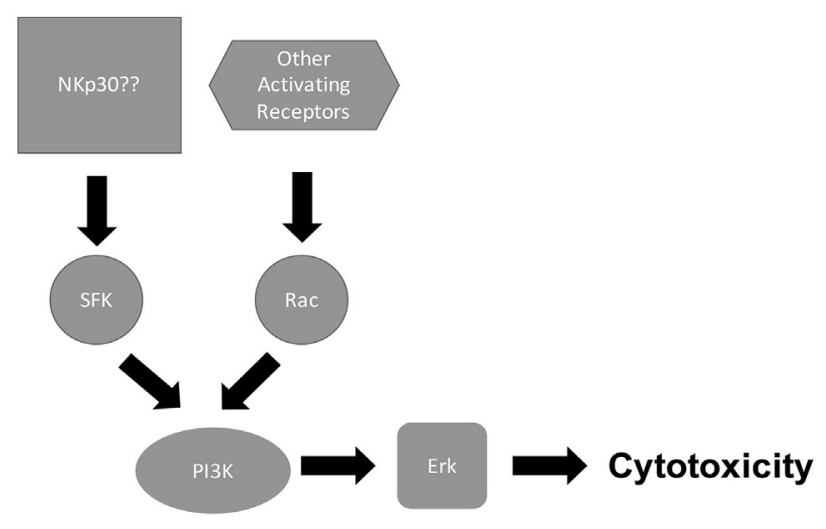

FIGURE 2 | Natural killer (NK) cell/Cryptococcus cytotoxicity pathway Following recognition of cryptococcal capsule and cell wall component by NK cell-activating receptors such as NKp30, receptor binding signals both Src family kinase (SFK) and Rac to activate PI3K/Erk, leading to cytotoxicity.

both Rac and SFK were found not to activate each other, but both were essential for PI3K activation in NK cell-mediated killing of Cryptococcus (15). In fact, Rac was found to be upstream of PI3K and was required for the activation of the PI3K $\rightarrow$ Erk signaling pathway during NK cell antifungal activity (15), thereby suggesting two separate pathways for PI3K activation (Figure 2). This interesting finding that Rac is upstream of PI3K needs to be confirmed by others. Ultimately, in tumor and cryptococcal killing, all pathways converged at Erk to mediate granule polarization and exocytosis, resulting in target cell death. The signaling pathway activated by the other known activating receptor for fungi cytotoxicity, NKp46, remains to be identified, and the signaling pathway involved in rearming of fungal cytotoxicity also remains to be investigated (42).

Tumor cells express several activating ligands on their surface to ligate NK cell-activating receptors, thereby resulting in multiple activating signaling pathways that contribute to cytotoxicity. For example, NKG2D binds the ULBP ligands, DNAM-1 binds CD112 and CD155, 2B4 binds CD48, and NKp30 binds B7-H6 (43). To date, the only known activating fungal ligands are three adhesins, Epa1, 6, and 7, of C. glabrata, which bind to NKp46 (29). Thus, whether there is coordination of signaling from multiple activating receptors expressed on NK cells to mediate fungi cytotoxicity remains an unanswered question.

\section{CYTOTOXIC GRANULE TRAFFICKING}

In response to tumor cells, coordinated signaling through different NK cell receptors and signaling molecules leads to polarization of cytotoxic granules toward the NK immune synapse (NKIS) formed with the target cell (44). The polarization of cytotoxic granules to the NKIS has been described in a sequential order. Upon conjugate formation with the target cell, the engagement of LFA-1 led to Vav1 activation (45). This in turn led to the polymerization and recruitment of filamentous actin (F-actin) to the NKIS (46). Dynein, a minus-end directed motor, rapidly moved granules along microtubules to converge on the microtubule-organizing center (MTOC) (47), followed by the polarization of the MTOC, together with the converged granules, to the NKIS (48). This process was mediated by kinesin-1, a plus-end motor that moves granules in the opposite direction, away from the MTOC (48). Although it is not clear how a kinesin would mediate MTOC movement to the NK cell synapse, in $\mathrm{T}$ cell cytotoxicity, the distal microtubule was tethered at the immune synapse and the MTOC was reeled in to the synapse by a dynein motor (49). Also, in T cell-mediated killing, microtubules linked the MTOC to the target contact site and the MTOC was progressively pulled to the contact site by a microtubule sliding mechanism (50). The MTOC movement resulted from the vector sum of tension on multiple microtubules (50). Following polarization, the lytic granules associated with myosin IIA, which enabled their interaction with F-actin and final transit through the actin-rich synapse to join the NK cell membrane (51). The contents of the cytolytic granules were then secreted directly toward the target cell through a pervasive F-actin network at the NKIS (52). While SFK signal mediated the rapid convergence of cytolytic granules to the MTOC without the involvement of PI3K, MEK, or PLC $\gamma$ (53), PI3K-Erk signal was required for the polarization of the MTOC and converged cytolytic granules to the NKIS $(32,44)$.

We are only beginning to understand the mechanisms by which cytotoxic granules traffic during fungal killing. Cytotoxic granule trafficking during NK cell cytotoxicity of Cryptococcus was different from that of tumors, especially because NK cells did not require LFA- 1 in the process, even though the $\beta 2$ chain of LFA- 1 bound to cryptococcal capsular components GXM and GalXM (14). Instead, NK cells used NKp30 to bind Cryptococcus and $C$. albicans, mediate microbial synapse formation, and signal PI3K-Erk to release perforin granules (7). Also the SFKs, Fyn and Lyn, redundantly mediated NK cell anticryptococcal activity by activating PI3K and Erk, which in turn polarized perforin-containing granules to the synapse (41). Furthermore, MTOC polarization toward the binding site with Cryptococcus was required for cryptococcal killing (54). It remains unknown whether a dynein is required for convergence of granules to the MTOC or whether a kinesin is required for polarization in response to fungi.

\section{IMPLICATION FOR THERAPEUTIC APPROACHES}

Understanding the receptors used and signaling pathways activated during NK cell function may lead to therapeutic opportunities. For example, compared to healthy adults, NK cells from HIV-infected patients had diminished expression of NKp30 (7), defective binding, reduced perforin content, defective perforin-containing granule polarization (55), reduced perforin release in response to Cryptococcus, and reduced cryptococcal killing $(7,55)$. Interestingly, treatment of NK cells from $\mathrm{HIV}$-infected patients with IL-12 reversed these multiple defects $(7,55)$. Since a percentage of HIV-infected patients are subclinically infected with $C$. neoformans (56), treatment 
with IL-12, or similar agent, could reduce or eliminate this complication. Another example is the development of pulmonary cryptococcosis and cryptococcal meningitis in patients with Crohn's disease or autoimmune hepatitis that were treated with the purine analog, azathioprine $(57,58)$. Azathioprine prevented Rac1 activation by blocking GTP binding to Rac1 $(59,60)$, and Rac1 activation in NK cells is required for NK cell cytotoxicity of tumors (32) and Cryptococcus (15). Thus, the increased susceptibility to Cryptococcus in patients with Crohn's disease and autoimmune hepatitis that are treated with azathioprine may in part be due to the defective NK cell function resulting from azathioprine-induced blockade of the $\mathrm{Rac} 1 \rightarrow \mathrm{PI} 3 \mathrm{~K} \rightarrow$ Erk cytotoxicity pathway.

\section{CONCLUDING REMARKS}

Fungi, like tumors, are susceptible to NK cell killing. While NK cells use multiple receptors to recognize and kill tumor cells (16), they use NKp30 to recognize and kill C. neoformans and $C$. albicans (7), and use NKp46 to kill C. glabrata (29). The paradigm in tumor cytotoxicity is that NK cells use multiple activating

\section{REFERENCES}

1. Kiessling R, Klein E, Wigzell H. "Natural" killer cells in the mouse. I. Cytotoxic cells with specificity for mouse Moloney leukemia cells. Specificity and distribution according to genotype. Eur J Immunol (1975) 5:112-7. doi:10.1002/ eji.1830050208

2. Herberman RB, Nunn ME, Lavrin DH. Natural cytotoxic reactivity of mouse lymphoid cells against syngeneic acid allogeneic tumors. I. Distribution of reactivity and specificity. Int J Cancer (1975) 16:216-29. doi:10.1002/ ijc. 2910160205

3. Schmidt S, Zimmermann SY, Tramsen L, Koehl U, Lehrnbecher T. Natural killer cells and antifungal host response. Clin Vaccine Immunol (2013) 20:452-8. doi:10.1128/CVI.00606-12

4. Moretta A, Marcenaro E, Parolini S, Ferlazzo G, Moretta L. NK cells at the interface between innate and adaptive immunity. Cell Death Differ (2008) 15:226-33. doi:10.1038/sj.cdd.4402170

5. Bryceson YT, March ME, Barber DF, Ljunggren HG, Long EO. Cytolytic granule polarization and degranulation controlled by different receptors in resting NK cells. J Exp Med (2005) 202:1001-12. doi:10.1084/jem. 20051143

6. Djeu JY, Jiang K, Wei S. A view to a kill: signals triggering cytotoxicity. Clin Cancer Res (2002) 8:636-40.

7. Li SS, Kyei SK, Timm-McCann M, Ogbomo H, Jones GJ, Shi M, et al. The NK receptor NKp30 mediates direct fungal recognition and killing and is diminished in NK cells from HIV-infected patients. Cell Host Microbe (2013) 14:387-97. doi:10.1016/j.chom.2013.09.007

8. Voigt J, Hunniger K, Bouzani M, Jacobsen ID, Barz D, Hube B, et al. Human natural killer cells acting as phagocytes against Candida albicans and mounting an inflammatory response that modulates neutrophil antifungal activity. J Infect Dis (2014) 209:616-26. doi:10.1093/infdis/jit574

9. Longhi LN, da Silva RM, Fornazim MC, Spago MC, de Oliveira RT, Nowill $\mathrm{AE}$, et al. Phenotypic and functional characterization of NK cells in human immune response against the dimorphic fungus Paracoccidioides brasiliensis. J Immunol (2012) 189:935-45. doi:10.4049/jimmunol.1102563

10. Bouzani M, Ok M, McCormick A, Ebel F, Kurzai O, Morton CO, et al. Human NK cells display important antifungal activity against Aspergillus fumigatus, which is directly mediated by IFN-gamma release. J Immunol (2011) 187:1369-76. doi:10.4049/jimmunol.1003593

11. Zhang T, Kawakami K, Qureshi MH, Okamura H, Kurimoto M, Saito A. Interleukin-12 (IL-12) and IL-18 synergistically induce the fungicidal activity of murine peritoneal exudate cells against Cryptococcus neoformans receptors to recognize tumor targets and the multiple NK cellactivating receptors cooperate to mediate tumor cytotoxicity. Interestingly, several fungi express multiple pattern-associated molecular patterns including adhesins (30), and NK cells used NKp46 to recognize the fungal adhesins Epa1, 6, and 7, which were expressed on C. glabrata (30). Further studies are needed to delineate other NK-activating receptors that could mediate fungal killing and to investigate whether cooperative recognition by multiple NK cell-activating receptors is required to mediate fungal cytotoxicity.

\section{AUTHOR CONTRIBUTIONS}

All the authors listed have made substantial, direct, and intellectual contribution to the work and approved it for publication.

\section{FUNDING}

This work was supported by grants from the Canadian Institute for Health Research (CIHR 365812 to CM), and the Jessie Bowden Lloyd Professorship in Immunology (CM).

through production of gamma interferon by natural killer cells. Infect Immun (1997) 65:3594-9.

12. Algarra I, Ortega E, Serrano MJ, Alvarez de Cienfuegos G, Gaforio JJ. Suppression of splenic macrophage Candida albicans phagocytosis following in vivo depletion of natural killer cells in immunocompetent BALB/c mice and T-cell-deficient nude mice. FEMS Immunol Med Microbiol (2002) 33:159-63. doi:10.1111/j.1574-695X.2002.tb00586.x

13. Bar E, Whitney PG, Moor K, Reis e Sousa C, LeibundGut-Landmann S. IL-17 regulates systemic fungal immunity by controlling the functional competence of NK cells. Immunity (2014) 40:117-27. doi:10.1016/j.immuni. 2013.12.002

14. Jones GJ, Wiseman JC, Marr KJ, Wei S, Djeu JY, Mody CH. In contrast to anti-tumor activity, YT cell and primary NK cell cytotoxicity for Cryptococcus neoformans bypasses LFA-1. Int Immunol (2009) 21:423-32. doi:10.1093/ intimm/dxp010

15. Xiang RF, Stack D, Huston SM, Li SS, Ogbomo H, Kyei SK, et al. Ras-related C3 botulinum toxin substrate (Rac) and Src family kinases (SFK) are proximal and essential for phosphatidylinositol 3-kinase (PI3K) activation in natural killer (NK) cell-mediated direct cytotoxicity against Cryptococcus neoformans. J Biol Chem (2016) 291:6912-22. doi:10.1074/jbc.M115. 681544

16. Moretta A, Bottino C, Vitale M, Pende D, Cantoni C, Mingari MC, et al. Activating receptors and coreceptors involved in human natural killer cell-mediated cytolysis. Annu Rev Immunol (2001) 19:197-223. doi:10.1146/ annurev.immunol.19.1.197

17. Bryceson YT, Ljunggren HG, Long EO. Minimal requirement for induction of natural cytotoxicity and intersection of activation signals by inhibitory receptors. Blood (2009) 114:2657-66. doi:10.1182/blood-2009-01201632

18. Bryceson YT, March ME, Ljunggren HG, Long EO. Activation, coactivation, and costimulation of resting human natural killer cells. Immunol Rev (2006) 214:73-91. doi:10.1111/j.1600-065X.2006.00457.x

19. Bryceson YT, March ME, Ljunggren HG, Long EO. Synergy among receptors on resting NK cells for the activation of natural cytotoxicity and cytokine secretion. Blood (2006) 107:159-66. doi:10.1182/blood-200504-1351

20. Castriconi R, Dondero A, Corrias MV, Lanino E, Pende D, Moretta L, et al. Natural killer cell-mediated killing of freshly isolated neuroblastoma cells: critical role of DNAX accessory molecule-1-poliovirus receptor interaction. Cancer Res (2004) 64:9180-4. doi:10.1158/0008-5472.CAN04-2682 
21. Glasner A, Ghadially H, Gur C, Stanietsky N, Tsukerman P, Enk J, et al. Recognition and prevention of tumor metastasis by the NK receptor NKp46/ NCR1. J Immunol (2012) 188:2509-15. doi:10.4049/jimmunol.1102461

22. Guerra N, Tan YX, Joncker NT, Choy A, Gallardo F, Xiong N, et al. NKG2Ddeficient mice are defective in tumor surveillance in models of spontaneous malignancy. Immunity (2008) 28:571-80. doi:10.1016/j.immuni.2008. 02.016

23. Halfteck GG, Elboim M, Gur C, Achdout H, Ghadially H, Mandelboim O. Enhanced in vivo growth of lymphoma tumors in the absence of the NK-activating receptor NKp46/NCR1. J Immunol (2009) 182:2221-30. doi:10.4049/jimmunol.0801878

24. Iguchi-Manaka A, Kai H, Yamashita Y, Shibata K, Tahara-Hanaoka S, Honda S, et al. Accelerated tumor growth in mice deficient in DNAM-1 receptor. J Exp Med (2008) 205:2959-64. doi:10.1084/jem.20081611

25. Pende D, Cantoni C, Rivera P, Vitale M, Castriconi R, Marcenaro S, et al. Role of NKG2D in tumor cell lysis mediated by human NK cells: cooperation with natural cytotoxicity receptors and capability of recognizing tumors of nonepithelial origin. Eur J Immunol (2001) 31:1076-86. doi:10.1002/1521-4141(200104)31:4<1076::AID-IMMU1076>3.0.CO;2-Y

26. Sivori S, Parolini S, Marcenaro E, Castriconi R, Pende D, Millo R, et al. Involvement of natural cytotoxicity receptors in human natural killer cell-mediated lysis of neuroblastoma and glioblastoma cell lines. J Neuroimmunol (2000) 107:220-5. doi:10.1016/S0165-5728(00) 00221-6

27. Smyth MJ, Swann J, Cretney E, Zerafa N, Yokoyama WM, Hayakawa Y. NKG2D function protects the host from tumor initiation. J Exp Med (2005) 202:583-8. doi:10.1084/jem.20050994

28. Alari-Pahissa E, Grandclement C, Jeevan-Raj B, Leclercq G, Veillette A, Held W. Activation by SLAM family receptors contributes to NK cell mediated "missing-self" recognition. PLoS One (2016) 11:e0153236. doi:10.1371/ journal.pone.0153236

29. Vitenshtein A, Charpak-Amikam Y, Yamin R, Bauman Y, Isaacson B, Stein N, et al. NK cell recognition of Candida glabrata through binding of NKp46 and NCR1 to fungal ligands Epa1, Epa6, and Epa7. Cell Host Microbe (2016) 20:527-34. doi:10.1016/j.chom.2016.09.008

30. de Groot PW, Bader O, de Boer AD, Weig M, Chauhan N. Adhesins in human fungal pathogens: glue with plenty of stick. Eukaryot Cell (2013) 12:470-81. doi:10.1128/EC.00364-12

31. Long EO, Kim HS, Liu D, Peterson ME, Rajagopalan S. Controlling natural killer cell responses: integration of signals for activation and inhibition. Annu Rev Immunol (2013) 31:227-58. doi:10.1146/annurev-immunol020711-075005

32. Jiang K, Zhong B, Gilvary DL, Corliss BC, Hong-Geller E, Wei S, et al. Pivotal role of phosphoinositide-3 kinase in regulation of cytotoxicity in natural killer cells. Nat Immunol (2000) 1:419-25. doi:10.1038/80859

33. Kim HS, Das A, Gross CC, Bryceson YT, Long EO. Synergistic signals for natural cytotoxicity are required to overcome inhibition by $\mathrm{c}-\mathrm{Cbl}$ ubiquitin ligase. Immunity (2010) 32:175-86. doi:10.1016/j.immuni.2010. 02.004

34. Crespo P, Schuebel KE, Ostrom AA, Gutkind JS, Bustelo XR. Phosphotyrosinedependent activation of Rac-1 GDP/GTP exchange by the vav proto-oncogene product. Nature (1997) 385:169-72. doi:10.1038/385169a0

35. Wiseman JC, Ma LL, Marr KJ, Jones GJ, Mody CH. Perforin-dependent cryptococcal microbicidal activity in NK cells requires PI3K-dependent ERK1/2 signaling. J Immunol (2007) 178:6456-64. doi:10.4049/jimmunol. 178.10 .6456

36. Xiong P, Sang HW, Zhu M. Critical roles of co-activation receptor DNAX accessory molecule-1 in natural killer cell immunity. Immunology (2015) 146:369-78. doi:10.1111/imm.12516

37. Billadeau DD, Upshaw JL, Schoon RA, Dick CJ, Leibson PJ. NKG2D-DAP10 triggers human NK cell-mediated killing via a Syk-independent regulatory pathway. Nat Immunol (2003) 4:557-64. doi:10.1038/ni929

38. Gilfillan S, Ho EL, Cella M, Yokoyama WM, Colonna M. NKG2D recruits two distinct adapters to trigger NK cell activation and costimulation. Nat Immunol (2002) 3:1150-5. doi:10.1038/ni857

39. Graham DB, Cella M, Giurisato E, Fujikawa K, Miletic AV, Kloeppel T, et al. Vav1 controls DAP10-mediated natural cytotoxicity by regulating actin and microtubule dynamics. J Immunol (2006) 177:2349-55. doi:10.4049/ jimmunol.177.4.2349
40. Upshaw JL, Arneson LN, Schoon RA, Dick CJ, Billadeau DD, Leibson PJ. NKG2D-mediated signaling requires a DAP10-bound Grb2-Vav1 intermediate and phosphatidylinositol-3-kinase in human natural killer cells. Nat Immunol (2006) 7:524-32. doi:10.1038/ni1325

41. Oykhman P, Timm-McCann M, Xiang RF, Islam A, Li SS, Stack D, et al. Requirement and redundancy of the Src family kinases Fyn and Lyn in perforin-dependent killing of Cryptococcus neoformans by NK cells. Infect Immun (2013) 81:3912-22. doi:10.1128/IAI.00533-13

42. Marr KJ, Jones GJ, Zheng C, Huston SM, Timm-McCann M, Islam A, et al. Cryptococcus neoformans directly stimulates perforin production and rearms NK cells for enhanced anticryptococcal microbicidal activity. Infect Immun (2009) 77:2436-46. doi:10.1128/IAI.01232-08

43. Chester C, Fritsch K, Kohrt HE. Natural killer cell immunomodulation: targeting activating, inhibitory, and co-stimulatory receptor signaling for cancer immunotherapy. Front Immunol (2015) 6:601. doi:10.3389/fimmu. 2015.00601

44. Chen X, Trivedi PP, Ge B, Krzewski K, Strominger JL. Many NK cell receptors activate ERK2 and JNK1 to trigger microtubule organizing center and granule polarization and cytotoxicity. Proc Natl Acad Sci U S A (2007) 104:6329-34. doi:10.1073/pnas.0611655104

45. Riteau B, Barber DF, Long EO. Vav1 phosphorylation is induced by beta2 integrin engagement on natural killer cells upstream of actin cytoskeleton and lipid raft reorganization. J Exp Med (2003) 198:469-74. doi:10.1084/ jem.20021995

46. Watzl C, Long EO. Signal transduction during activation and inhibition of natural killer cells. Curr Protoc Immunol (2010) Chapter 11:Unit 11 9B. doi:10.1002/0471142735.im1109bs90

47. Mentlik AN, Sanborn KB, Holzbaur EL, Orange JS. Rapid lytic granule convergence to the MTOC in natural killer cells is dependent on dynein but not cytolytic commitment. Mol Biol Cell (2010) 21:2241-56. doi:10.1091/mbc. E09-11-0930

48. Tuli A, Thiery J, James AM, Michelet X, Sharma M, Garg S, et al. Arf-like GTPase Arl8b regulates lytic granule polarization and natural killer cell-mediated cytotoxicity. Mol Biol Cell (2013) 24:3721-35. doi:10.1091/mbc. E13-05-0259

49. Yi J, Wu X, Chung AH, Chen JK, Kapoor TM, Hammer JA. Centrosome repositioning in $\mathrm{T}$ cells is biphasic and driven by microtubule end-on capture-shrinkage. J Cell Biol (2013) 202:779-92. doi:10.1083/jcb. 201301004

50. Kuhn JR, Poenie M. Dynamic polarization of the microtubule cytoskeleton during CTL-mediated killing. Immunity (2002) 16:111-21. doi:10.1016/ S1074-7613(02)00262-5

51. Sanborn KB, Rak GD, Maru SY, Demers K, Difeo A, Martignetti JA, et al. Myosin IIA associates with NK cell lytic granules to enable their interaction with F-actin and function at the immunological synapse. J Immunol (2009) 182:6969-84. doi:10.4049/jimmunol.0804337

52. Rak GD, Mace EM, Banerjee PP, Svitkina T, Orange JS. Natural killer cell lytic granule secretion occurs through a pervasive actin network at the immune synapse. PLoS Biol (2011) 9:e1001151. doi:10.1371/journal.pbio. 1001151

53. James AM, Hsu HT, Dongre P, Uzel G, Mace EM, Banerjee PP, et al. Rapid activation receptor- or IL-2-induced lytic granule convergence in human natural killer cells requires Src, but not downstream signaling. Blood (2013) 121:2627-37. doi:10.1182/blood-2012-06-437012

54. Hidore MR, Mislan TW, Murphy JW. Responses of murine natural killer cells to binding of the fungal target Cryptococcus neoformans. Infect Immun (1991) 59:1489-99.

55. Kyei SK, Ogbomo H, Li S, Timm-McCann M, Xiang RF, Huston SM, et al. Mechanisms by which interleukin-12 corrects defective NK cell anticryptococcal activity in HIV-infected patients. MBio (2016) 7. doi:10.1128/ mBio.00878-16

56. Sawadogo S, Makumbi B, Purfield A, Ndjavera C, Mutandi G, Maher A, et al. Estimated prevalence of Cryptococcus antigenemia (CrAg) among HIV-infected adults with advanced immunosuppression in Namibia justifies routine screening and preemptive treatment. PLoS One (2016) 11:e0161830. doi:10.1371/journal.pone.0161830

57. Fraison JB, Guilpain P, Schiffmann A, Veyrac M, Le Moing V, Rispail P, et al. Pulmonary cryptococcosis in a patient with Crohn's disease treated with prednisone, azathioprine and adalimumab: exposure to chicken manure 
as a source of contamination. J Crohns Colitis (2013) 7:e11-4. doi:10.1016/ j.crohns.2012.04.016

58. Sethi NK, Torgovnick J, Sethi PK. Cryptococcal meningitis after imuran (azathioprine) therapy for autoimmune hepatitis. Eur J Gastroenterol Hepatol (2007) 19:913-4. doi:10.1097/MEG.0b013e3282cf4ed9

59. Neurath M. Thiopurines in IBD: what is their mechanism of action? Gastroenterol Hepatol (N Y) (2010) 6:435-6.

60. Tiede I, Fritz G, Strand S, Poppe D, Dvorsky R, Strand D, et al. CD28dependent Racl activation is the molecular target of azathioprine in primary human CD4+ T lymphocytes. J Clin Invest (2003) 111:1133-45. doi:10.1172/ JCI16432
Conflict of Interest Statement: The authors declare that the research was conducted in the absence of any commercial or financial relationships that could be construed as a potential conflict of interest.

Copyright $\odot 2017$ Ogbomo and Mody. This is an open-access article distributed under the terms of the Creative Commons Attribution License (CC BY). The use, distribution or reproduction in other forums is permitted, provided the original author(s) or licensor are credited and that the original publication in this journal is cited, in accordance with accepted academic practice. No use, distribution or reproduction is permitted which does not comply with these terms. 